\title{
CHARACTERIZATION OF HAZELNUT OIL EXTRACTED BY ULTRASOUND ASSISTED SOLVENT EXTRACTION
}

\author{
CHIN HONG GEOW ${ }^{1}$, MEI CHING TAN ${ }^{1 *}$ and NYUK LING CHIN ${ }^{2}$ \\ ${ }^{1}$ Department of Chemical and Petroleum Engineering, Faculty of Engineering, \\ Technology and Built Environment, UCSI University, 56000 Cheras Kuala Lumpur, Malaysia \\ ${ }^{2}$ Department of Process and Food Engineering, Faculty of Engineering, Universiti Putra Malaysia, \\ 43000 UPM Serdang, Selangor Malaysia \\ *E-mail:tanmc@ucsiuniversity.edu.my
}

Accepted 8 September 2020, Published online 25 October 2020

\begin{abstract}
In this study, ultrasound treatment was used to enhance the oil yield of hazelnut oil. The oil was extracted by using hexane with 15 min ultrasound treatment initially. Ultrasound amplitude (30,60 and 90\%), solvent to solid ratio $(6: 1,8: 1$ and $10: 1 \mathrm{~mL} / \mathrm{g})$ and extraction temperatures $\left(28,38\right.$ and $\left.48^{\circ} \mathrm{C}\right)$ gave positive effect on oil yield. Higher oil yield of $88.78 \%$ was achieved at highest settings of ultrasound amplitude, solvent to solid ratio and temperature as compared to $69.57 \%$ obtained from the lowest settings of those parameters. Characterization of extracted oil in terms of iodine value, acid value, and peroxide value were carried out in this study. The results showed that ultrasound treatment would not significantly $(p>0.10)$ affect those values. All the values obtained were in the range of acceptable levels for edible oil. In term of fatty acid, gas chromatograph analysis results showed that around $9 \%$ of saturated and $91 \%$ of unsaturated fatty acids were observed in hazelnut oil for all the amplitudes applied. More crack structures were observed on the surface of hazelnut samples after ultrasound treatment under scanning electron microscopy images, which could enhance the oil yield. This concluded that extraction with ultrasound aid could be used as an alternative extraction method for hazelnut oil with no negative impact on oil quality.
\end{abstract}

Key words: Ultrasound, hexane, solvent extraction, hazelnut oil

\section{INTRODUCTION}

Edible oils and fats have wide applications in the world. In food processing, edible oils can be used to produce butter, which is an emulsion of water and oil, mayonnaise, salad cream, chocolate, etc. Edible oil can be extracted from various seeds, beans or nuts such as rapeseed (Citeau et al., 2018), soybean (Toda et al., 2016) and hazelnut (Lv et al., 2017). Hazelnut is one of the main crops for many countries, including USA, Turkey, Iran, Australia, Spain, Chile and Italy (Mehra et al., 2015). Hazelnut contains a lot of minerals and vitamins (Kalkan et al., 2017). Those vitamins are mainly oil soluble which can act as an antioxidant to prevent lipid oxidation in human body (Kalkan et al., 2017). It is also one of the sources of fiber which has high nutritional functions for human (Mehra et al., 2015). The oil contents in hazelnut is considered as a

* To whom correspondence should be addressed. highly valuable product since most of the fatty acids are unsaturated fatty acids (Özkal et al., 2005). Hazelnut oil has been widely used in cosmetic industry as the skin absorbs it quickly due to large amount of unsaturated fatty acids which makes the hazelnut oil suitable to produce protective cream (Kalkan et al., 2017). The major fatty acid compositions for hazelnut oil are palmitic acid (C16:0, 6\%), stearic acid (C18:0, 3\%), oleic acid (C18:1, 79\%) and linoleic acid (C18:2, 10\%) (Özkal et al., 2005). It is believed that unsaturated fatty acid is able to reduce "bad cholesterol" which is low density lipoprotein in human body (Orem et al., 2013).

Various alternative extraction methods are developed to improve the edible oil extraction yield in shorter extraction time. Many researches have conducted an oil extraction using various extraction methods including super critical carbon dioxide extraction of Hibiscus cannabinus L. seed oil (Chan \& Ismail, 2009), extraction of papaya seed oil with 
ultrasound aid (Samaram et al., 2015), solvent assisted extraction of oil from Moringa oleifera Lam. seeds (Bhutada et al., 2016), etc. Ultrasound aid in extraction is a simple process to extract the edible oil meanwhile also produce high yield and shorten the extraction time (Samaram et al., 2014). This is because ultrasound application creates vibration in liquid medium which causes the bubble formation in liquid (Chemat et al., 2017). The bubble formed will then collapse and produce cavitation effect. Cavitation can cause the formation of micro-cracks on the surface of solid due to the release of high energy when the bubble is collapsed (Geow et al., 2018). In the extraction of edible oil, the sample in powder form can be considered as a solid phase where the cavitation effect will increase the number of micro-cracks and surface area of sample (Tekin et al., 2015). Therefore, more oil content is able to diffuse out from the micro-cracks which will increase the oil yield (Perrier et al., 2017; Geow et al., 2018).

In food industry, it is very important to have the knowledge of lipid analysis. This is to identify whether the quality of oil or fat is suitable for food application. Many issues have risen concerning the impact of dietary fat on health and food-labeling requirements (Nielsen, 2010). Characterization of lipid in terms of iodine value, acid value and peroxide value are normally carried out for lipid analysis in food industry (Nielsen, 2010). Iodine analysis can be used to determine the degree of total unsaturation of oil or fat (Nielsen, 2010). Iodine value can affect some of the important properties of edible oil such as oxidation stability. It shows the tendency for oil or fat to be oxidized. Besides, acid value is normally represented the amount of fatty acid that hydrolyzed from triacylglycerol. Free fatty acid estimates the amount of oil that will be lost during refining step as it is required to remove the fatty acid. Furthermore, peroxide value is one of the parameters used to determine whether the primary oxidation product is hydroperoxide. The principle of it is the liberation of iodine from potassium iodide due to the presence of peroxide. A general peroxide value for edible oil should be less than $20 \mathrm{mEq} / \mathrm{kg}$ oil to prevent rancidity flavor (Kong \& Singh, 2011).

The aim of this study is to investigate the effect of ultrasound as a treatment in solvent extraction of hazelnut oil. The impacts of ultrasound amplitude, solvent to solid ratio and extraction temperature on oil yield were studied. The quality of extracted oil was determined in term of iodine value, free fatty acid value and peroxide value while the fatty acid compositions in the extracted oil were investigated using gas chromatograph analysis. Furthermore, the sample structure before and after extraction was investigated through scanning electron microscope to prove the ultrasound cavitation effect, which creates the micro-cracks on the solid sample.

\section{MATERIALS AND METHODS}

\begin{abstract}
Materials
Hazelnut powder (grounded, USA) was purchased from Sunday Bakery Ingredients, Malaysia. Hexane (95\% purity, Grade AR), ethanol (95\% purity, Grade AR), acetic acid (glacial), phenolphthalein, sodium hydroxide pellets, sodium thiosulphate, chloroform, Wijs solution, potassium iodide, soluble starch, sodium methoxide powder (95\% purity, Grade AR), sodium chloride and sodium sulphate were purchased from Evergreen Engineering and Resources, Malaysia. Gas chromatography capillary column (HP-88, $30 \mathrm{~m} \times$ $0.25 \mathrm{~mm} \times 0.20 \mu \mathrm{m}$, Agilent, USA) and Supelco 37 Component FAME Mix (varied concentration in dichloromethane) were purchased from IT Tech Research (M) Sdn Bhd, Malaysia.
\end{abstract}

\section{Ultrasound assisted extraction}

Approximately $15 \mathrm{~g}$ of grounded hazelnut powder was added into $90 \mathrm{~mL}$ of hexane. The suspension was then sonicated at $30 \%$ ultrasound amplitude for $15 \mathrm{~min}$ by using a $130 \mathrm{~W}, 20 \mathrm{kHz}$ ultrasound probe system (SONICS, VCX130, Australia) with on-off cycle of $10 \mathrm{~s}$ sonication and $5 \mathrm{~s}$ pulse duration. After ultrasound pretreatment, the extraction was carried out on hot plate stirrer (Dragon Lab, MS-H280-PRO, China) at $600 \mathrm{rpm}$ and $28^{\circ} \mathrm{C}$ room temperature for $2 \mathrm{hr}$. The solid was then separated out from suspension by using Buchner funnel under vacuum condition. The solvent was then evaporated from extracted liquid by using rotary evaporator (BUCHI, R-200, Switzerland) at $40^{\circ} \mathrm{C}$ and $93 \mathrm{rpm}$ under vacuum conditions. The mass of oil recovered per gram of hazelnut powder was recorded as $m_{r}$. The three-level full factorial design was used to study the effect of the three factors, i.e. ultrasound amplitude (30, 60 and 90\%), solvent to solid ratio $(6: 1,8: 1$ and $10: 1 \mathrm{~mL} / \mathrm{g})$ and temperature $\left(28,38\right.$ and $\left.48^{\circ} \mathrm{C}\right)$ on extracted oil yield.

\section{Iodine value}

Iodine value test was carried out following the standard procedures in Food Analysis Laboratory Manual (Nielsen, 2010). The oil sample was filtered through filter paper to remove the impurities. Approximately $0.3 \mathrm{~g}$ of oil was weighed into 500 $\mathrm{mL}$ conical flask with stopper and $10 \mathrm{~mL}$ of chloroform with $25 \mathrm{~mL}$ of Wijs solution were added into the flask. The flask was then kept in dark condition for $30 \mathrm{~min}$ with occasional shaking. After incubation in dark condition, $20 \mathrm{~mL}$ of $15 \%$ 
potassium iodide solution was added into the flask and shaken vigorously. The iodine in the flask was titrated with standard $0.1 \mathrm{M}$ of sodium thiosulphate gradually until the yellow colour almost disappeared. Approximately $2 \mathrm{~mL}$ volume of $1 \%$ starch indicator was then added into the flask and titration was continued until the blue colour entirely disappeared. The total volume of sodium thiosulphate used was recorded and the iodine value was determined by using Eq. (1) (Nielsen, 2010).

Iodine value $=\frac{(B-S) \times N \times 126.9}{W} \times 100$

Where, $B$ and $S$ represents the total volume $(\mathrm{mL})$ required for blank and sample respectively. $N$ is normality of sodium thiosulphate $(\mathrm{mol} / \mathrm{mL}), 126.9$ is the molecular weight of iodine $(\mathrm{g} / \mathrm{mol})$ and $W$ is the mass of sample $(\mathrm{g})$.

\section{Free fatty acid value}

Free fatty acid (FFA) value analysis was carried out following the standard procedures in Food Analysis Laboratory Manual (Nielsen, 2010). Firstly, oil sample was filtered through a filter paper. Approximately $5 \mathrm{~g}$ aliquot of oil was weighed into a $250 \mathrm{~mL}$ conical flask and $100 \mathrm{~mL}$ of neutralized ethanol with $2 \mathrm{~mL}$ of phenolphthalein indicator were then added into the flask. The mixture was shaken to dissolve completely. The mixture was then titrated with $0.1 \mathrm{M}$ sodium hydroxide solution and shaken vigorously until the end point was reached. The total volume of sodium hydroxide used was recorded. FFA value was determined by using Eq. (2) (Nielsen, 2010).

$\% \mathrm{FFA}=\frac{V \times N \times 282}{W} \times 100$

where, $V$ is the volume of sodium hydroxide used, is the normality of sodium hydroxide $(\mathrm{mol} / \mathrm{mL}), 282$ is the molecular weight of oleic acid $(\mathrm{g} / \mathrm{mol})$ and is the weight of sample $(\mathrm{g})$.

\section{Peroxide value}

Peroxide value test was carried out following the standard procedures in Food Analysis Laboratory Manual (Nielsen, 2010). The oil was first filtered thorough filter paper and $5 \mathrm{~g}$ of oil was weighed into a $250 \mathrm{~mL}$ conical flask with stopper. Approximately $30 \mathrm{~mL}$ of acetic-acid chloroform solution $(3: 2)$ was added into the flask and swirled to dissolve. After that, $0.5 \mathrm{~mL}$ volume of saturated potassium iodide solution was added into the flask and shaken occasionally for $1 \mathrm{~min}$. Approximately $30 \mathrm{~mL}$ of distilled water was added after shaking. The sample was then titrated with $0.1 \mathrm{M}$ sodium thiosulphate solution with vigorously shaking until the yellow colour was almost disappeared. Approximately $0.5 \mathrm{~mL}$ volume of $1 \%$ starch indicator was added into the flask and titration was continued until the blue colour just disappeared. The total volume of sodium thiosulphate used was recorded and peroxide value was determined by using Eq. (3) (Nielsen, 2010).

Peroxide value $=\frac{(S-B) \times N}{W} \times 100$

Where, and are the total volume of sodium thiosulphate $(\mathrm{mL})$ used for sample and blank respectively is the normality of sodium thipsulphate $(\mathrm{mol} / \mathrm{mL})$ and is the weight of sample $(\mathrm{g})$.

\section{Gas chromatography analysis}

Fatty acid composition in the extracted oil was identified and quantified by using gas chromatography (GC) analysis. Firstly, the oil sample was converted to fatty acid methyl ester (FAME) by sodium methoxide method following the standard procedures in Food Analysis Laboratory Manual (Nielsen, 2010). The FAME analysis was then carried by using gas chromatograph, with front ionization detector (Agilent, 7890A, USA), equipped with HP-88 capillary column $(30 \mathrm{~m} \times 0.25 \mathrm{~mm} \times 0.2 \mu \mathrm{m})$. The instrument condition setting was done by following standard procedures (Nielsen, 2010). The peaks obtained from sample analysis were compared with the peaks obtained from Supelco 37 Component FAME Mix for fatty acid identification purpose. Peak area was then calculated for quantification purpose, which presented in percentage of total area.

\section{Scanning electron microscopy}

The surface morphology of raw hazelnut and defatted flakes after oil extraction were examined using scanning electron microscopy (JEOL, JSMIT100, Japan). The samples were coated with gold layer using sputter coater (BALTEC, SCD005, USA) before viewing. The SEM images were captured at 1000 magnification.

\section{Experimental design and statistical analysis}

All the experiment was carried out in duplicate and the results were expressed as mean values. The statistical analysis was carried out by ANOVA using Microsoft Excel 2013 (Version 15, Microsoft Corporation, USA). 


\section{RESULTS AND DISCUSSION}

\section{Oil yield}

The effect of ultrasound amplitude, solvent to solid ratio and extraction temperature on oil yield is shown in Figure 1. The highest oil yield of $88.78 \%$ was obtained at ultrasound amplitude of $90 \%$ when the extraction was carried out at the highest solvent to solid ratio of 10:1 and extraction temperature of $48^{\circ} \mathrm{C}$. However, the lowest yield of $69.57 \%$ was obtained at ultrasound amplitude of $30 \%$ when the lowest solvent to solid ratio of $6: 1$ and extraction temperature of $28^{\circ} \mathrm{C}$ was applied. At the same solvent to solid ratio and extraction temperature, the results showed that the oil yield increased from ultrasound amplitude of $30 \%$ to $90 \%$. This might be due to more cavitation effect induced at increasing ultrasound amplitude which caused more damage on the cell wall of sample thus increased the amount of oil diffused out from the solid sample (Kuriakose, 2015). Mechanical vibration of ultrasound wave during the treatment had furthermore caused larger contact in surface area between the hexane solvent and hazelnut powder which enabled more solvent to penetrate into the sample easily and subsequently increased the oil yield (Samaram et al., 2015). Besides, the study on ultrasound assisted oil extraction from rice bran has reported that the increase of oil yield through swelling and rehydrating of cells is due to tissue matrix fragmentation (Toma et al., 2001; Kuriakose, 2015). The similar behavior was reported in ultrasound assisted extraction of rapeseed oil (Perrier et al., 2017), rice bran oil (Kuriakose, 2015) and pumpkin seed oil (Hernández-Santos et al., 2016).

Figure 1 showed that the oil yield increased with extraction temperature. The oil yield increase from $79.08 \%$ to $88.78 \%$ as the extraction temperature increased from $28^{\circ} \mathrm{C}$ to $48^{\circ} \mathrm{C}$ at the highest ultrasound amplitude of $90 \%$ and solvent to solid ratio of 10:1. This could be because higher temperature will increase the solubility of oil in the solvent which could increase the oil yield (Zhang et al., 2009; Bhutada et al., 2016). However, increasing the processing temperature will increase the production cost from the industrial point of view and might lead to oil oxidation (Tian et al., 2013). Therefore, extraction temperature cannot be too high and must be carefully selected based on the type of solvent used to prevent the evaporation of solvent during the extraction process. Besides, vapor pressure of solvent increased at higher extraction temperature which could decrease the surface tension and viscosity of the solvent (Tekin et al., 2015). Subsequently, it enhances the ultrasound cavitation effect where the cell wall could disrupt effectively (Tekin et al., 2015). Therefore, more oil content was able to be diffused out from the sample into solvent. The results were similar as reported in solvent assisted extraction of clove essential oil (Tekin et al., 2015), Moringa oleifera Lam. seed oil (Bhutada et al., 2016) and almond oil (Zhang et al., 2009).

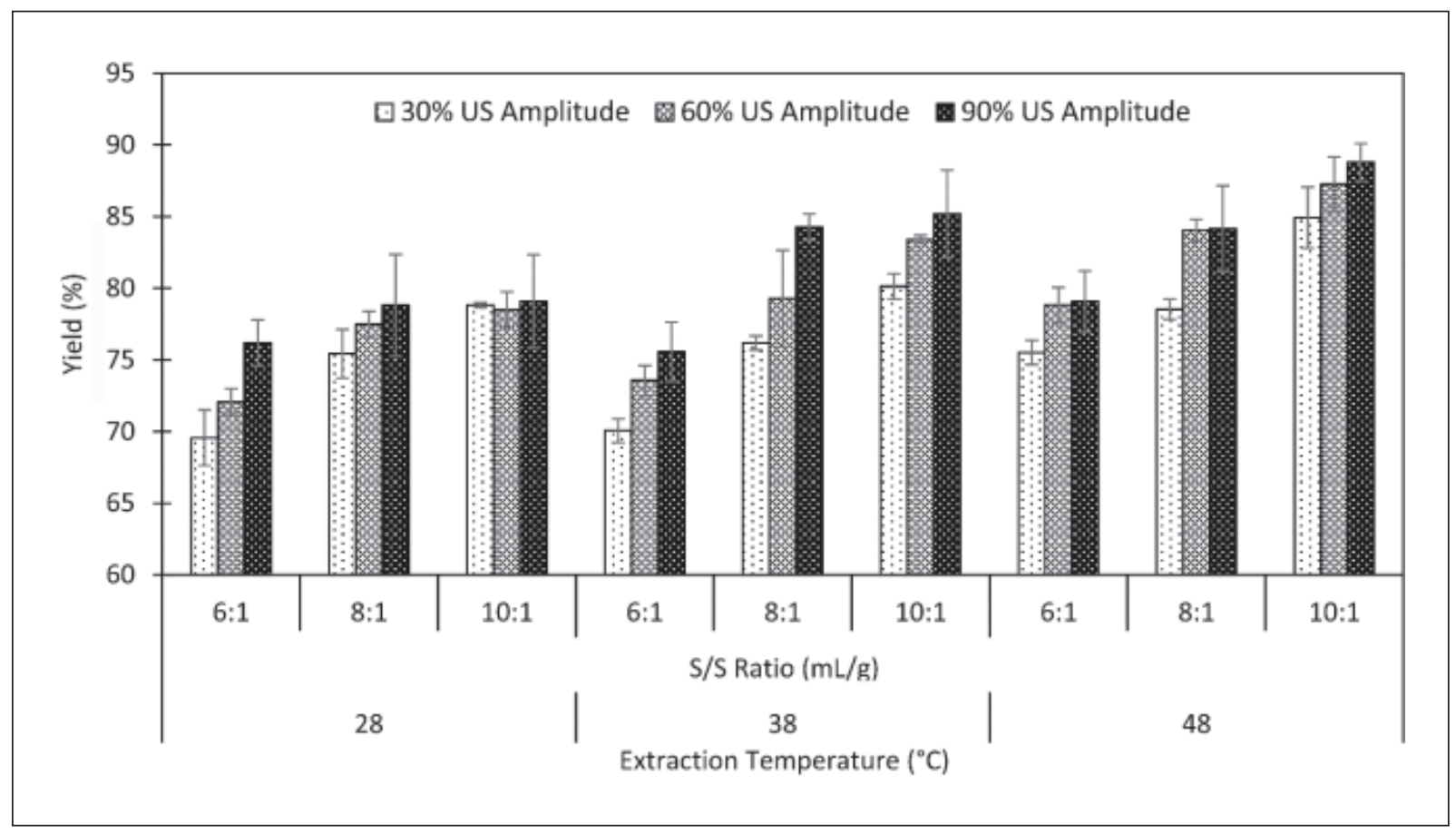

Fig. 1. Effect of ultrasound amplitude, solvent to solid ratio and extraction temperature on oil yield. 
In terms of solvent to solid ratio, higher oil yield was obtained when higher solvent to solid ratio was applied as illustrated in Figure 1. The oil yield increased from $79.07 \%$ to $88.78 \%$ as the solvent to solid ratio increased from $6: 1$ to $10: 1$ at the highest ultrasound amplitude of $90 \%$ and extraction temperature of $48^{\circ} \mathrm{C}$. The amount of oil yield is depend on its mass transfer during the extraction process which is related to the concentration gradient between the solvent and solid sample (Zhang et al., 2008; Zhang et al., 2009). Higher oil yield obtained at higher solvent to solid ratio might be due to the increase of concentration gradient which allows more oil content to be diffused out from the solid sample into bulk solvent (Anvar, 2009; Zhang et al., 2009; Tian et al., 2013). However, the changes of oil yield obtained when the ratio increased from 8:1 to 10:1 was lesser as compared to $6: 1$ to $8: 1$. Therefore, further increasing the solvent to solid ratio was not an effective way to increase the oil yield as it could cause the waste of solvent. The results were similar as reported in ultrasound assisted extraction of almond oil (Zhang et al., 2009) and pomegranate seed oil (Tian et al., 2013).

\section{Iodine value}

Oil and fat mainly contain saturated and unsaturated fatty acid and most of their properties depend on the ratio of these fatty acid (Gunstone, 2009). Figure 2 shows the iodine value of oil samples extracted at different ultrasound amplitude. The results showed that ultrasound treatment would not significantly affect the iodine value of oil sample. Based on the results, around $40 \mathrm{~g}$ of iodine absorbed per $100 \mathrm{~g}$ of oil sample for all the cases.
There is no significant change $(p>0.10)$ in iodine value between the control and treated oil samples. This can conclude that ultrasound treatment will not affect the fatty acid compositions of oil samples in terms of saturated and unsaturated fatty acids. The findings were comparable to ultrasonic extraction of olive, sunflower, sesame and tallow olein oils where the iodine values have no significant changes when treated with $0,25,60$ and $100 \%$ ultrasound amplitude (Hosseini et al., 2015).

\section{Acidity value}

Acidity value can be used to determine the quality of oil where higher value indicating oil oxidation occurs (Uquiche et al., 2008; Kuriakose, 2015). Figure 3 shows the \%FFA in oil samples extracted at different ultrasound amplitude. The results showed that the \%FAA was between 0.80 to $0.90 \mathrm{~g} / 100 \mathrm{~g}$ of oil for all the ultrasound amplitudes applied. The quality of oil samples were good as the acid values were considered low (Hernández-Santos et al., 2016). Hazelnut oil obtained in this study was comparable to pumpkin seed oil obtained through ultrasonic extraction which has the acid value ranged from 1.94 to 3.69 (Hernández-Santos et al., 2016). In this study, it could be observed that ultrasound amplitude would not significantly $(p>0.50)$ affect the quality of oil in term of free fatty acid values. Therefore, it could be an alternative pathway to extract the edible hazelnut oil as it able to maintain the acidity value below $4 \mathrm{~g} / 100 \mathrm{~g}$ of oil. The findings were agreed with previous study on ultrasound assisted extraction of Pistacia Khinjuk hull oil (Bagher et al., 2016) and papaya seed oil (Samaram et al., 2013).

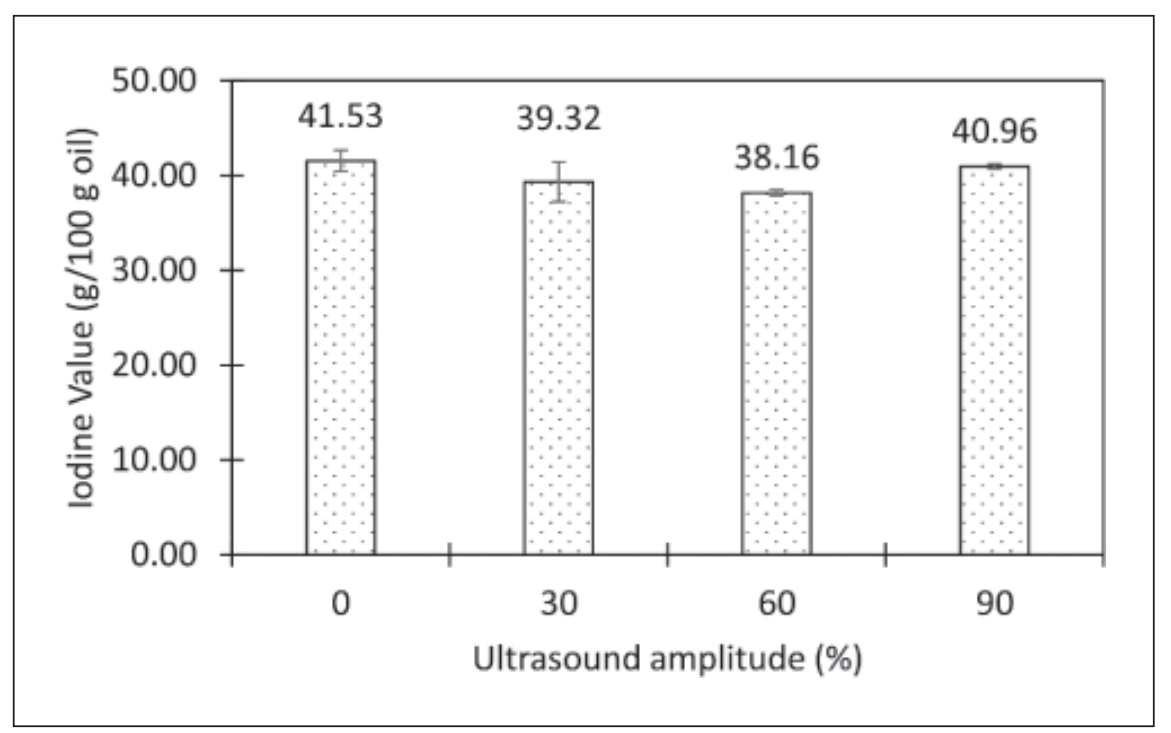

Fig. 2. Iodine value of oil samples extracted at different ultrasound amplitude at 10:1 solvent to solid ratio and $48^{\circ} \mathrm{C}$ extraction temperature. 


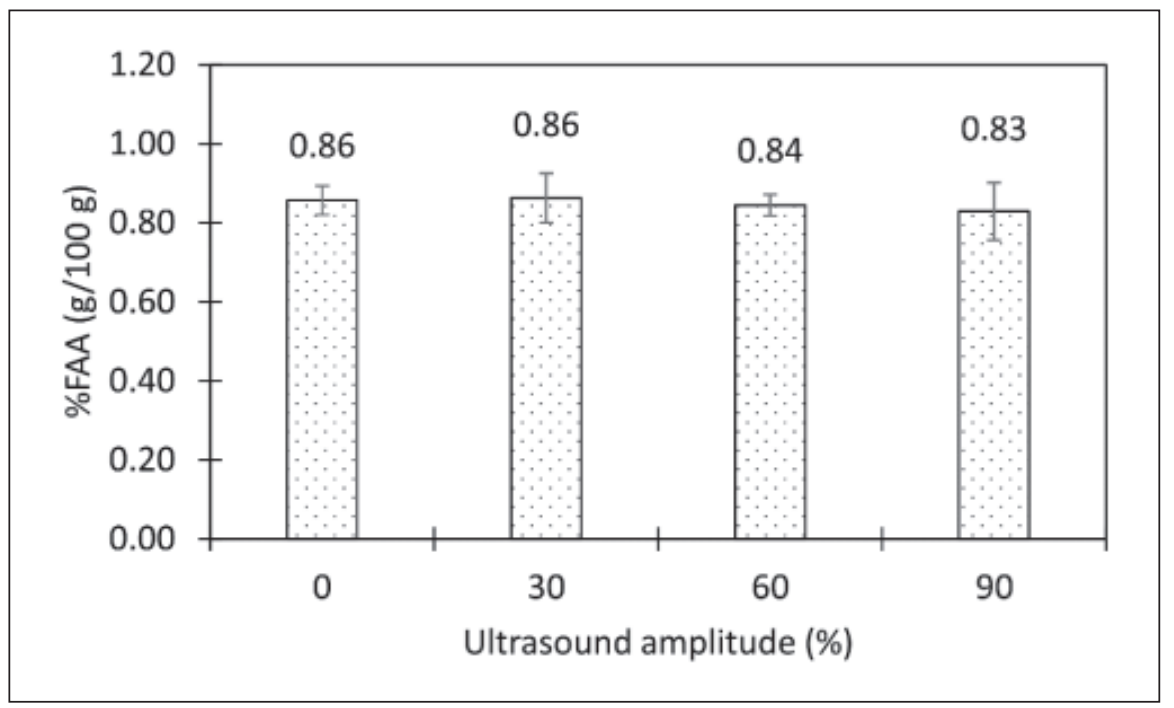

Fig. 3. Free fatty acid of oil samples extracted at different ultrasound amplitude at 10:1 solvent to solid ratio and $48^{\circ} \mathrm{C}$ extraction temperature.

\section{Peroxide value}

Lipid oxidation is caused by the formation of primary and secondary oxidation products (Bagher et al., 2016). Figure 4 illustrates the peroxide value of oil samples extracted at different ultrasound amplitude. The results showed that the peroxide value was around $2-3 \mathrm{mEq} / \mathrm{kg}$ for all the ultrasound amplitude applied, which indicated that the extracted oil was stable due to its low peroxide value (Hernández-Santos et al., 2016). From the results obtained, ultrasound application has no significant effect on lipid oxidation $(p>0.50)$ as there is no obvious changes on the peroxide values, thus the oil quality can be maintained. Therefore, ultrasound assisted solvent extraction could become an alternative method to extract the hazelnut oil. The results were similar to previous study which reported that ultrasound assisted extraction did not significantly change the peroxide value of Pistacia Khinjuk hull oil (Bagher et al., 2016). Furthermore, the stability of hazelnut oil was comparable to pumpkin seed oil obtained through ultrasonic extraction with peroxide value between 1.6 and $4.6 \mathrm{mEq} / \mathrm{kg}$ oil (Hernández-Santos et al., 2016).

\section{Fatty acid compositions}

The fatty acid profiles of hazelnut oil extracted at various amplitude were determined by gas chromatography analysis and the results are shown in Table 1. In term of saturated fatty acids, there were around $6 \%$ of palmitic acid and $3 \%$ of stearic acid found in hazelnut oil for all the ultrasound amplitude applied. Based on the results, the oil mainly composed of high percentage of unsaturated fatty acid. It showed that around $81 \%$ of oleic acid and $10 \%$ of linoleic acid were found in hazelnut oil.
Hazelnut could be classified as unsaturated oil which contains oleic and linoleic acid in large percentages (Teixeira et al., 2018). The results showed that ultrasound application would not change the fatty acid compositions in hazelnut oil. Free fatty acids were formed by the hydrolysis of triglycerides under moisture conditions (Hosseini et al., 2015). Therefore, this showed that ultrasound treatment did not have direct effect on hydrolysis reaction and would not affect the quality of oil in term of saturated and unsaturated fatty acids. The compositions of fatty acids obtained in this study was similar as theoretical compositions (Gunstone, 2011).

\section{SEM analysis}

The SEM images of raw hazelnut and defatted flakes after ultrasound assisted extraction at various amplitudes are shown in Figure 5. It can be observed that more oil was reserved in the raw hazelnut before extraction as presented in Figure 5(a). The cells that contain oil became beeswax shape after solvent extraction indicated that the oil has been diffused out from the cell into solvent. Ultrasound treatment has successfully created more pathways for oil diffusion through cavitation effect. Figure 5(c), 5(d) and 5(e) showed that the number of cracks formed was increased with ultrasound amplitude. More cracks could be observed as compared to the control as shown in Figure 5(b). This phenomenon could explain the effect of ultrasound treatment on oil yield. As more pathways were provided during solvent extraction, oil content in the cell could be easily released through the openings (Perrier et al., 2017). This can conclude that ultrasound amplitude has positive effect in oil yield. Another research has 


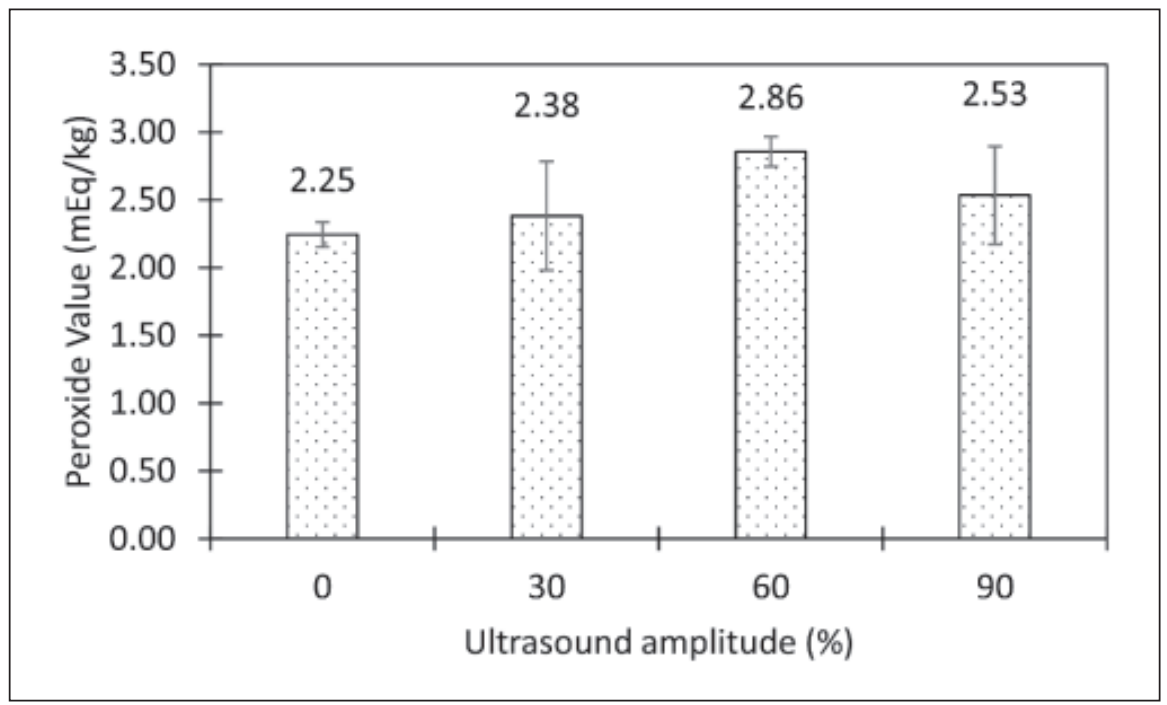

Fig. 4. Peroxide value of oil samples extracted at different ultrasound amplitude at 10:1 solvent to solid ratio and $48^{\circ} \mathrm{C}$ extraction temperature.

Table 1. Fatty acid compositions of oil extracted at different ultrasound amplitude at $10: 1$ solvent to solid ratio and $48^{\circ} \mathrm{C}$ extraction temperature

\begin{tabular}{lcccc}
\hline \multirow{2}{*}{ Fatty acid (\%) } & \multicolumn{4}{c}{ Ultrasound amplitude (\%) } \\
\cline { 2 - 5 } & 0 & 30 & 60 & 90 \\
\hline C16:0 (Palmitic acid) & 5.87 & 5.67 & 5.81 & 6.02 \\
C18:0 (Stearic acid) & 2.83 & 2.78 & 2.82 & 2.93 \\
C18:1, cis (Oleic acid) & 81.27 & 81.45 & 81.24 & 81.02 \\
C18:2, cis (Linoleic acid) & 10.03 & 10.10 & 10.14 & 10.04 \\
\hline
\end{tabular}

reported that ultrasound was able to enhance the oil yield of rapeseed oil by cavitation effect which proved by more cracks observed under SEM images of rapeseed flakes defatted with hexane (Perrier et al., 2017).

\section{CONCLUSION}

Hazelnut oil was successfully extracted by using hexane solvent extraction and further enhanced with ultrasound treatment. The results showed that increasing ultrasound amplitude, solvent to solid ratio and extraction temperature could increase the oil yield. Maximum oil yield of $88.78 \%$ was obtained when all the study factors were at the highest setting while minimum oil yield of $69.57 \%$ was obtained at the lowest setting. Characterization of extracted hazelnut oil showed that ultrasound treatment would not significantly affect the oil quality $(p>0.10)$. Iodine value, acid value and peroxide value of oil extracted were around $40 \mathrm{~g}$ iodine per $100 \mathrm{~g}$ of oil, 0.08 to $0.9 \mathrm{~g}$ per $100 \mathrm{~g}$ of oil and 2 to $3 \mathrm{mEq} / \mathrm{kg}$ of oil respectively. GC analysis showed that around $91 \%$ of fatty acids in hazelnut oil was unsaturated which is suitable to be used as edible oil. SEM images revealed that more crack structures were observed when the ultrasound amplitude was increased. This concluded that ultrasound can be used as a treatment to extract hazelnut oil with higher yield and without affect the oil quality.

\section{ACKNOWLEDGEMENT}

This work was supported by the UCSI University, Malaysia, through the Pioneer Scientist Incentive Fund (Proj-2019-FETBE-061).

\section{REFERENCES}

Anvar, S. 2009. Ultrasound-assisted extraction of oil from tea seeds. Journal of Food Lipids, 16(4): $465-474$. 


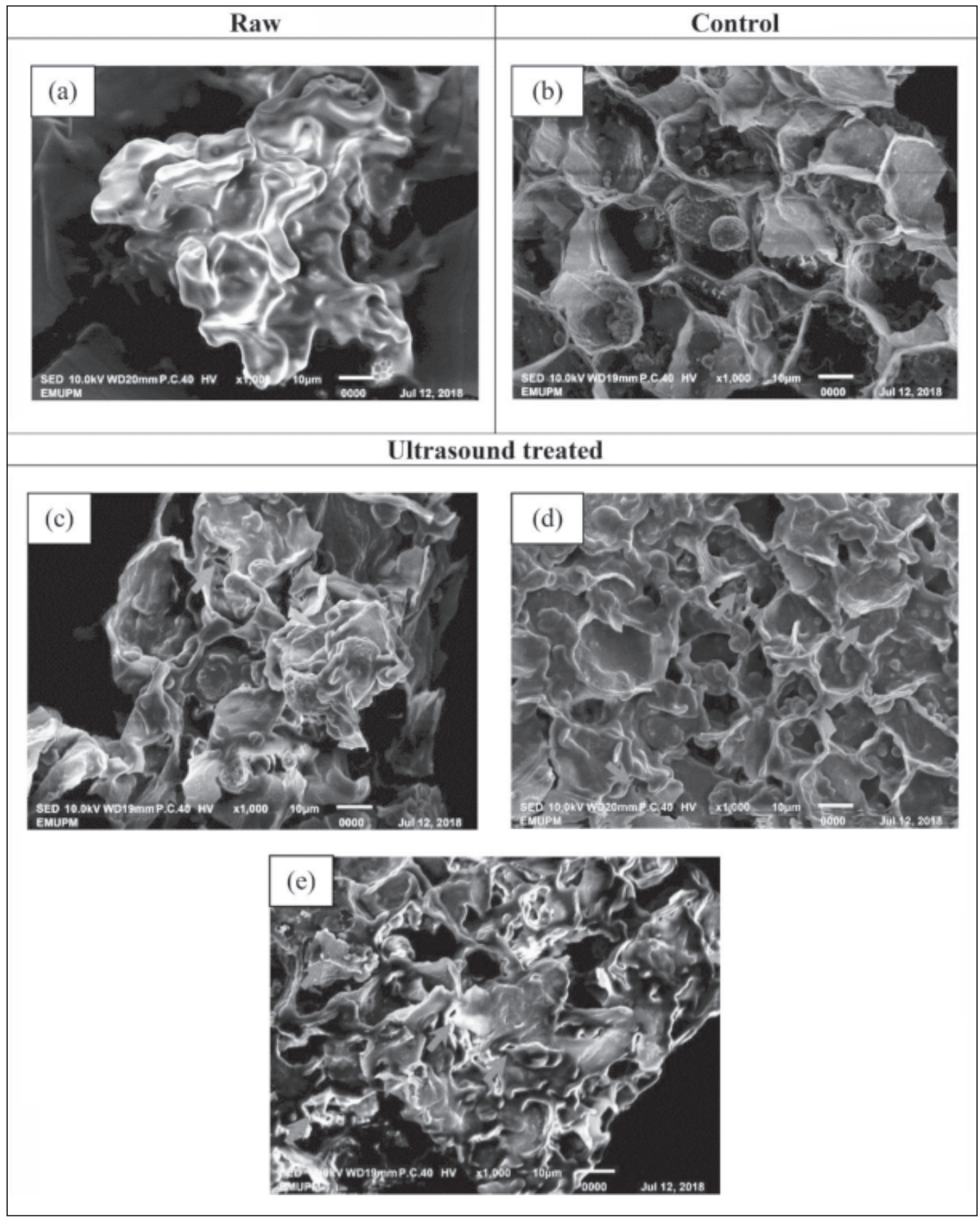

Fig. 5. Image of SEM (magnification: $\times 1000$ ) for (a) oil reserve in raw hazelnut and pore structures observed after ultrasound assisted extraction for (b) control, (c) 30\%, (d) $60 \%$ and (e) $90 \%$ amplitude.

Bagher, S.M., Khaneghah, A.M. \& Akbarirad, H. 2016. The effects of amplitudes ultrasoundassisted solvent extraction and pretreatment time on the yield and quality of Pistacia Khinjuk hull oil. Journal of Oleo Science, 65(9): 733-738.

Bhutada, P.R., Jadhav, A.J., Pinjari, D.V., Nemade, P.R. \& Jain, R.D. 2016. Solvent assisted extraction of oil from Moringa oleifera Lam. seeds. Industrial Crops and Products, 82: 7480 .
Chan, K.W. \& Ismail, M. 2009. Supercritical carbon dioxide fluid extraction of Hibiscus cannabinus L. seed oil: A potential solvent-free and high antioxidative edible oil. Food Chemistry, 114(3): 970-975.

Chemat, F., Rombaut, N., Sicaire, A.G., Meullemiestre, A., Fabiano-Tixier, A.S. \& Abert-Vian, M. 2017. Ultrasound assisted extraction of food and natural products. Mechanisms, techniques, combinations, protocols and applications. A review. Ultrasonics Sonochemistry. 
Geow, C.H., Tan, M.C., Yeap, S.P. \& Chin, N.L. 2018. A Box-Behnken design for optimization of ultrasound-assisted solvent extraction of hazelnut oil. Journal of Food Processing and Preservation, 42(9): e13743.

Gunstone, F.D. 2009. Oils and Fats in the Food Industry: Food Industry Briefing Series. WileyBlackwell, Oxford.

Gunstone, F.D. 2011. Vegetable Oils in Food Technology: Composition, Properties and Uses. 2nd Ed. John Wiley \& Sons, United States.

Hernández-Santos, B., Rodríguez-Miranda, J., Herman-Lara, E., Torruco-Uco, J.G., CarmonaGarcía, R., Juárez-Barrientos, J.M. \& MartínezSánchez, C.E. 2016. Effect of oil extraction assisted by ultrasound on the physicochemical properties and fatty acid profile of pumpkin seed oil (Cucurbita pepo). Ultrasonics Sonochemistry, 31: 429-436.

Hosseini, S., Gharachorloo, M., Tarzi, B.G., Ghavami, M. \& Bakhoda, H. 2015. Effects of Ultrasound Amplitude on the Physicochemical Properties of Some Edible Oils. JAOCS, Journal of the American Oil Chemists' Society, 92(1112): 1717-1724.

Kalkan, F., Vanga, S.K., Murugesan, R., Orsat, V. \& Raghavan, V. 2017. Microencapsulation of hazelnut oil through spray drying. Drying Technology, 35(5): 527-533.

Kuriakose, K.V. 2015. Ultrasound Assisted Extraction of Oil from Rice Bran: A Response Surface Methodology Approach. Journal of Food Processing \& Technology, 6(454): 2.

Mehra, M., Chiesa, A.E. \& Sirotnak, A.P. 2015. Two cases of sublingual hematoma as a manifestation of child abuse. Ear, Nose and Throat Journal, 94(12): 494-496.

Nielsen, S. 2010. Food Analysis Laboratory Manual. Springer, Switzerland. pp. 103-113.

Orem, A., Yucesan, F.B., Orem, C., Akcan, B., Kural, B.V., Alasalvar, C. \& Shahidi, F. 2013. Hazelnut-enriched diet improves cardiovascular risk biomarkers beyond a lipid-lowering effect in hypercholesterolemic subjects. Journal of Clinical Lipidology, 7(2): 123-131.

Özkal, S.G., Salgin, U. \& Yener, M.E. 2005. Supercritical carbon dioxide extraction of hazelnut oil. Journal of Food Engineering, 69(2): 217-223.

Perrier, A., Delsart, C., Boussetta, N., Grimi, N., Citeau, M. \& Vorobiev, E. 2017. Effect of ultrasound and green solvents addition on the oil extraction efficiency from rapeseed flakes. Ultrasonics Sonochemistry, 39: 58-65.
Samaram, S., Mirhosseini, H., Tan, C.P. \& Ghazali, H.M. 2013. Ultrasound-assisted extraction (UAE) and solvent extraction of papaya seed oil: Yield, fatty acid composition and triacylglycerol profile. Molecules, 18(10): 12474-12487.

Samaram, S., Mirhosseini, H., Tan, C.P. \& Ghazali, H.M. 2014. Ultrasound-assisted extraction and solvent extraction of papaya seed oil: Crystallization and thermal behavior, saturation degree, color and oxidative stability. Industrial Crops and Products, 52: 702-708.

Samaram, S., Mirhosseini, H., Tan, C.P., Ghazali, H.M., Bordbar, S. \& Serjouie, A. 2015. Optimisation of ultrasound-assisted extraction of oil from papaya seed by response surface methodology: Oil recovery, radical scavenging antioxidant activity, and oxidation stability. Food Chemistry, 172: 7-17.

Teixeira, G.L., Ghazani, S.M., Corazza, M.L., Marangoni, A.G. \& Ribani, R.H. 2018. Assessment of subcritical propane, supercritical $\mathrm{CO} 2$ and Soxhlet extraction of oil from sapucaia (Lecythis pisonis) nuts. Journal of Supercritical Fluids, 133: 122-132.

Tekin, K., Akalin, M.K. \& Şeker, M.G. 2015. Ultrasound bath-assisted extraction of essential oils from clove using central composite design. Industrial Crops and Products, 77: 954-960.

Tian, Y., Xu, Z., Zheng, B. \& Martin Lo, Y. 2013. Optimization of ultrasonic-assisted extraction of pomegranate (Punica granatum L.) seed oil. Ultrasonics Sonochemistry, 20(1): 202-208.

Toma, M., Vinatoru, M., Paniwnyk, L. \& Mason, T.J. 2001. Investigation of the effects of ultrasound on vegetal tissues during solvent extraction. Ultrasonics Sonochemistry, 8(2): 137-142.

Uquiche, E., Jeréz, M. \& Ortíz, J. 2008. Effect of pretreatment with microwaves on mechanical extraction yield and quality of vegetable oil from Chilean hazelnuts (Gevuina avellana Mol). Innovative Food Science and Emerging Technologies, 9(4): 495-500.

Zhang, Q.A., Zhang, Z.Q., Yue, X.F., Fan, X.H., Li, T. \& Chen, S.F. 2009. Response surface optimization of ultrasound-assisted oil extraction from autoclaved almond powder. Food Chemistry, 116(2): 513-518.

Zhang, Z.S., Wang, L.J., Li, D., Jiao, S., Chen, X. \& Mao, Z.H. 2008. Ultrasound assisted extraction of oil from flaxseed. Sep. Purif. Technol., 62(1): 192-198. 
